\title{
EL PENSAMIENTO SOCIAL EN BRASIL. ESTILOS, IDIOMAS. ENTREVISTA CON LUIZ ANTONIO DE CASTRO SANTOS ${ }^{1}$
}

El 14 de diciembre tuvo lugar el lanzamiento del libro O pensamento social no Brasil. Estilos, idiomas en la librería Martins Fontes de la ciudad de São Paulo (Brasil). Semanas después, a principios de febrero, la editorial sugiere realizar la entrevista que se publica, en primer lugar, en el Blog da EdUERJ [https://www.eduerj.com/blog], y en la presente versión de forma ampliada y revisada, para la $R E B$.

Luiz Antonio de Castro Santos es sociólogo; máster en Ciencias por la Escuela de Salud Pública de Harvard (1974) y PhD en Sociología, también por la Universidad de Harvard (1987). Es profesor visitante de la Universidad Federal de Sur da Bahía (mayo 2015 - mayo 2017), profesor visitante del programa de post-graduación en Sociología política, de la Universidad Federal de Santa Catarina, desde junio de 2018 y profesor asociado de la UERJ, institución de la cual se jubiló en febrero de 2015. Es investigador del CNPq. En el año 2000, recibió la medalla del Centenario de la Fundación Oswaldo Cruz, por su contribución relevante a la investigación histórica y sociológica en salud pública en Brasil. Se dedica a temas del pensamiento social en Brasil y

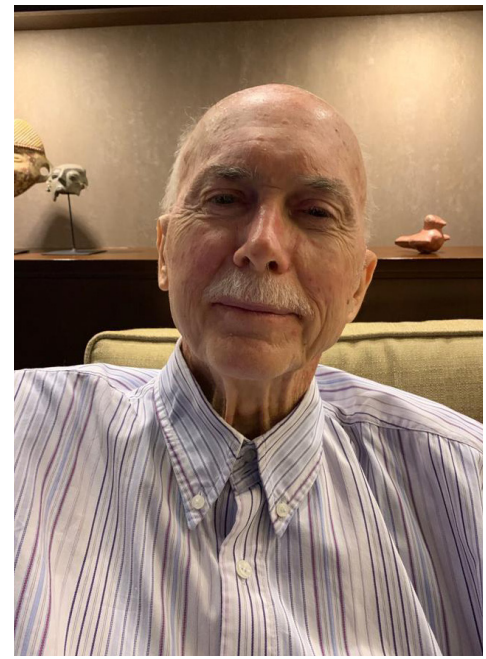

Fotografia: Luiz Antonio de Castro Santos. Fonte: Acervo pessoal. de teorías sociológicas; a la sociología e Historia de la salud y al estudio de las representaciones sociales. Encabeza el grupo de investigación del CNPq sobre instituciones y representaciones de la salud. Entre sus libros publicados recientemente destacan Contrapontos: ensaios sobre saúde e sociedade (Río de Janeiro: EdUERJ, 2013); Comitês de ética em pesquisa: caminhos e descaminhos teórico-metodologógicos, volumen especial de la Revista Brasileira de Sociologia (enero - junio 2015; Castro Santos, L. A. \& Jeolás, L. Orgs); Saúde, sociedade, protagonismos (São Paulo: Hucitec, 2018; en coautoría con Lina Faria) y O pensamento social no Brasil. Estilos, idiomas (Río de Janeiro: EdUERJ \& Gramma Editores, 2017, $2^{\circ}$ ed.), siendo este el tema principal de la entrevista concedida por el autor, ahora publicada en la $R E B$.

\section{Ricardo Zentgraf}

Periodista. Asesor de comunicación de la Editora UERJ, Universidad Estatal de Río de Janeiro (UERJ, Brasil).

zentgraf@hotmail.com

\section{Mariana Leoni Birriel}

Doctoranda en Sociología política de la Universidad Federal de Santa Catarina (UFSC, Brasil).

marianaleoni87@gmail.com 


\section{Investigadores brasileños}

Ricardo Zentgraf: Usted enfoca su trabajo en la producción de los intelectuales vinculados al pensamiento social brasileño. Me gustaría que hablara sobre el impacto que supone proponer tal debate en los días actuales.

Luiz Antonio de Castro Santos: Afortunadamente el debate aún es posible, más allá de que no se acerque a una probabilidad estadística. Por otro lado, justamente es lo imponderable lo que me atrae, visto que de lo contrario sería medir "factores de impacto" que de hecho traicionan más de lo que revelan la importancia o el valor de lo que leemos hoy.

Hace algunos años la revista Lua Nova publicó un excelente debate sobre el tema. El título remite directamente al texto en la web: "Simposio: cinco cuestiones sobre el pensamiento social brasileño". Creo que lo que motivó la organización del simposio fue una mesa en un congreso de ANPOCS, coordinada por André Botelho y Lilia Moritz Schwarcz. Ahí encontramos una óptima y reciente oportunidad para una perspectiva optimista. De Angélica Madeira a Sérgio Miceli, las declaraciones revelan al lector algo raro en el mundo académico, a saber: casi todos se leen, jo nos leemos! Esto obviamente puede ser un "factor de impacto" en la búsqueda de alcanzar al lector.

Si nos centramos en una de las cinco cuestiones, "¿Qué libros o artículos del área destacaría?", las declaraciones sugieren un buen intercambio. Son citados con alguna frecuencia los trabajos de Sérgio Miceli, Angela Alonso, Eduardo Jardim de Moraes, Elide Rugai Bastos, Renan Freitas Pinto, Lilia M. Moritz Schwarcz, Roberto Ventura, Ricardo Benzaquen, Luiz Werneck Vianna, entre otra decena de autores, lo que muestra el intercambio que he mencionado. Finalmente, y siendo importantísimo, como recuerdan las declaraciones de Werneck Vianna y Roberto Motta, allí están "Nuestros Clásicos": recuerdo la valiosa colección de librillos con ese título, publicados por la antigua Editora Agir- Gilberto Freyre y Sérgio Buarque de Holanda. En fin, el debate está en el aire, disputando un lugar en el torrente de temas relevantes que nos llaman la atención y nos fuerzan a hacer elecciones difíciles en el día a día.

Recuerdo aquí un artículo muy oportuno, de Naomar de Almeida Filho, "Nunca fuimos flexnerianos" (pero antes lo fuimos, porque Flexner no fue nada de lo que se dice de él). Me gustaría parafrasearlo: "Nunca fuimos hegemónicos", diría a Sérgio Tavolaro, que escribió una contundente "Crítica a un discurso hegemónico". Sin embargo, antes lo fuimos...

Si recuerdo la importante contribución, a inicios del siglo XX, de Abraham Flexner, educador en el área de la Salud y la Medicina, es para traer a colación una cuestión que quedó un poco al margen del Simposio y que, sin embargo, considero fundamental: el modo en el que la Salud y la Educación forjaron, no sólo el Pensamiento Social en nuestro país (como lo hicieron en Estados Unidos y en Europa, de modo indiscutible), sino también las bases para la construcción de un Estado-Nación. Hasta el día de hoy, esto tiene un impacto desfavorable entre nosotros, o dio margen a un cierto "benign neglect" en relación al Pensamiento Social en Salud, en particular a la Sociología y a la Historia de la Salud Pública. Basta recordar aquí, compensando la falta de atención en este aspecto, que aún en la Primera República, en 1924, la creación de la Asociación Brasileña de Educación derivó de un movimiento colectivo de educadores como Bertha Lutz, de científicos como Miguel Osório de Almeida y de sanitaristas como Belisário Penna. El hecho de que los militantes del Estado-Nación (me permito recordar un
PALABRAS CLAVE

Pensamiento

social;

investigación sociológica;

formación de

investigadores, tradición

brasileña, tradición norteamericana; Harvard.

PALAVRAS-CHAVE Pensamento

social; pesquisa sociológica; formação de pesquisador;

tradição brasileira; tradição norteamericana;

Harvard.

KEYWORDS

Social Thought; Sociological Inquiry; traditions of research; Brazil; USA. 
tema puesto a prueba en la obra de André Botelho, sobre Ronald de Carvalho y su participación en los momentos decisivos del Estado-Nación) se unieran en uno de los movimientos ideológicos más fuertes de la Primera República, que delineaba los rumbos de una Democracia sobre los marcos de la "Nacionalización de la Salud", de la "Socialización de la Educación", de la "Equiparación de los Sexos" y de la "Consagración de la Libertad", entre sus ideas clave -todas influenciadas por el pensamiento de Bertha Lutz- debería merecer la atención del Simposio. Esto no sucedió y fue una pena.

\section{Clásicos del Pensamiento Social}

RZ: Su libro trae reflexiones sobre autores como Pereira Barreto, Azevedo Sodré, Arthur Neiva, Belisário Pena y Sérgio Buarque de Holanda. ¿Cuál fue el punto crucial que lo llevó a escribir sobre estos nombres?

Luiz Antonio de Castro Santos: Sérgio Buarque es y será siempre un "punto crucial”. Hoy, más que nunca, pues leo, perplejo, un torrente de interpretaciones erradas sobre su obra, en particular Raíces del Brasil. Pero aún Visión del Paraíso, "evitada" por la crítica reciente, anda un tanto descuidada.

Me gustaría posicionarme en relación a Raíces del Brasil. Brevemente. Después sobre Visión del Paraíso, objeto del capítulo cinco de mi libro. Raíces del Brasil, obra inicialmente publicada en 1936, recibió un prefacio extraordinariamente explicativo de Antonio Candido a la quinta edición, de 1969. Suelo decirles a mis alumnos que no se trata de un prefacio cualquiera. Es una lectura obligatoria. Y, de forma curiosa, siempre se me viene a la cabeza la idea de que sus críticos más acérrimos, entre los cuales se alinea/desalinea el Profesor Jessé de Souza, jamás leyeron este prefacio. Porque Antonio Candido de hecho coloca el libro en su contexto "enraizado", en su época de fecundación y germinación. No caben interpretaciones que, a propósito, se coloquen fuera de contexto. La lectura del prefacio evita algo que se está convirtiendo en una moda en nuestros cursos de ciencias humanas, que es rotular, para no leer. Por ejemplo, "Gilberto Freyre creó el mito de que somos una democracia racial". No es verdad, los lectores de buena fe de Gilberto deben leer a Oracy Nogueira y su distinción del preconcepto de marca (herencia del Brasil esclavista) y el preconcepto de origen (herencia de los Estados Unidos esclavistas)-lectura fundamental para releer a Gilberto. Sin preconceptos.

Y hoy tenemos el ejemplo funesto de que Sérgio Buarque de Holanda inventó al "hombre cordial" brasileño. E inventó nuestra "pretendida herencia patrimonial-patriarcal" (cito aquí un trecho de un libro muy importante, de Sérgio Tavolaro). Tendría que retirar, por lo pronto, el adjetivo "pretendida" -pues aquella herencia, muy bien estudiada por "Nuestros Clásicos", es la argamasa que revistió y reviste nuestro presente de desigualdades brutales, injusticias e identidades sociales rasgadas- de punta a punta, desde nuestra juventud sin rumbo a los ancianos abandonados; de las clases obreras a los sin techo y sin tierra. Pues bien, ese es el punto que remite a las tonterías enunciadas por los críticos de Sérgio Buarque sobre la "cordialidad". Es necesario que entendamos el concepto, en Sérgio, como una contraposición a la "civilidad". Somos "cordiales" no porque seamos "buenos", sino porque no incorporamos, en nuestra sociabilidad, la capacidad de distinguir el espacio público, de un lado, de la vida privada, del otro. La cordialidad es el espacio de los afectos. El término viene del latín, "cor, cordis", corazón... Nuestros intereses son pautados, no por el sentido de colectividad, sino por el sentido de familia, de casa-grande, de mi territorio y de mi herencia de nombre y tradición... Hay un trecho en la obra Laberinto de la Soledad, del ensayista mexicano Octavio Paz, que habla justamente de la "cordialidad" en su país: "traición y lealtad yacen hondo en nuestra mirada".

Sobre Visión del Paraíso tendría un poco más que decir, pero ya lo hice en el capítulo que titulé, a modo de provocación, "Invitación a Todorov para leer a Sérgio Buarque de Holanda". En pocas palabras, 
mi artículo busca revelar que Visión del Paraíso discute, con inmensa erudición, la conquista "de las Américas", mientras que el ensayista rumano se centra apenas en el Caribe y en México. Pero el título de su obra, traducido a nivel internacional, es engañoso: La Conquista de las Américas. Y el subtítulo evoca la voz del Otro conquistado: pero paradójicamente es apenas la voz de uno de los pueblos. Sérgio da voz a las Américas y a sus pueblos, no sólo a un pueblo de las Américas.

Me gustaría comentar dos curiosidades. La primera la tentación, que contuve, de rebautizar el capítulo con el nombre "Invitación al profesor Jessé a leer a Sérgio Buarque de Holanda". La segunda es quizá más oportuna. Sucede que el capítulo sobre Visión del Paraíso fue preparado para un Coloquio sobre Sérgio Buarque de Holanda, organizado por Dirce Côrtes Riedel en la Universidad del Estado de Río de Janeiro (UERJ), en 1991. Éramos pocos participantes, pero fue excelente. Cuando terminé mi presentación (una primera versión del capítulo actual), empezó un debate entre nosotros, y yo defendí una postura que les pareció quizá antipática: que Sérgio era poco leído (salvo por Raíces), incluso en Brasil. Sin embargo, todos estuvieron de acuerdo en que él tenía un perfil intelectual excepcional, más sólido que el de Todorov. Pero en el escenario brasileño irrumpía nuestra vieja subalternidad frente al viejo mundo... Recuerdo que mi amigo fraterno e historiador, Antonio Carlos Peixoto, no estuvo de acuerdo: Sérgio era, sí, muy leído y respetado en el exterior. Respondí que su obra era para "lecturas periféricas", o para lectores de la LASA - o sea, en un ambiente restringido de estudios latinoamericanos. Y Todorov, no - él era "universal", europeo y esas cosas.

Bueno, la discusión terminó ahí, o un poco después, en un restaurante de Tijuca. Pero semanas después se celebraba el "descubrimiento" de América. Y el periódico Folha de São Paulo, creo que en el Caderno Mais, anunciaba, en la primera página, un texto conmemorativo. Fui directo al texto. Imaginé: será alguna reseña sobre Visión del Paraíso. "Menudo error". Era un comentario o reseña sobre la obra... de Todorov. En casa del herrero, cuchillo de palo. La recorté y se la mandé a mi amigo Peixoto...

\section{Formación de un sociólogo brasileño, años '70}

RZ: Gilberto Freyre se destaca en su libro, siendo analizado en cuatro capítulos, al contrario de los restantes autores escogidos. ¿Cómo fue el proceso de creación de este material? Aún más, uno de los capítulos trata del impacto de Gilberto en la historiografía norteamericana. ¿Cómo se da esta contribución?

Luiz Antonio de Castro Santos: El proceso de creación tuvo inicio en la segunda mitad de la década de 1970, durante mi doctorado en el departamento de sociología de la universidad de Harvard, en Cambridge, Massachusetts. Teníamos que producir un "paper teórico" y pasar por un "qualifying" cuantitativo. Nunca fui bueno en métodos cuantitativos y decidí realizar algunos cursos introductorios al otro lado de Harvard Yard, en la facultad de Educación, que era precaria, claramente una unidad de Harvard destinada a producir magísteres y doctores "del tercer mundo". Pero aprendí lo básico, que se mantiene hasta hoy en día.

En lo que respecta al texto de carácter teórico, decidí escribir sobre Gilberto Freyre, justamente porque su impacto en la historiografía norteamericana había sido considerable y en aquellos años de 1970 la moda ya había pasado - y yo lo que quería era retornar el tema, traerlo nuevamente a los colegas y profesores que, con pocas excepciones, no lo conocían. Al principio pensé en compararlo, desde varios ángulos, con la trayectoria de Florestan Fernandes - en ese momento exiliado en Canadá y con buena traducción de sus textos al inglés. El paper suponía un requisito para el máster en sociología y el tema no podía, bajo ningún concepto, ser el mismo que el de la tesis, para la cual yo ya había decidido 
realizar un estudio histórico-sociológico de la salud en Brasil. Otra curiosidad: no pude recibir el título de máster en Sociología, ya que había que hacer un pago a la Universidad y el CNPq me informó de que yo ya había realizado un máster en Estados Unidos, lo que de hecho era cierto. En caso de que decida pagar, el título está allí, esperándome, desde hace 40 años...

Me gustaría recordar un escenario totalmente diferente al actual: los plazos eran sumamente flexibles, inicié mi doctorado en 1974, volví a Brasil en 1979 (todo aprobado por el CNPq), interrumpí mi tesis para trabajar y solo volví a Estados Unidos años más tarde. A propósito, esta flexibilidad era muy oportuna, ya que evitaba, en aquellos tiempos - y evitaría hoy en día- el caudal de trabajos académicos y tesis horrorosas, hechas a última hora, por imposiciones de tiempo que vienen de CAPES y que deberían ser revisadas. Sé que estas carreras atléticas en la vida académica también se dan fuera de Brasil, en Europa y Estados Unidos, pero esto es un problema de allá y no debemos doblegarnos a padrones de medida de producciones que son generados allí fuera. Claro que no todo está perdido. Estoy tocando un punto clave. La declaración de Lucia Lippi en el Simposio que cité antes, trae, justamente, cinco tesis excelentes de doctorado en ciencias humanas, defendidas recientemente. Pero me preocupa el gasto de ríos de dinero público en la formación de una posgraduación deficiente y con posdoctorados a veces turísticos, mientras que las bases de la formación -la Educación Básica y la Escuela Pública - permanecen sobre arenas movedizas en Brasil.

Pero volviendo a Gilberto Freyre, debo enfatizar que el tema de ese "paper teórico" había sido aprobado por un comité departamental, que luego juzgaría la calidad del texto. Tuve cierta dificultad, inicialmente, porque a los miembros del comité no les gustó mi idea de un estudio comparativo entre Gilberto Freyre y Florestan Fernandes. David Maybury-Lewis (que era miembro del comité, aun siendo del departamento vecino, de Antropología) consideró que la tarea era demasiado ardua en relación a lo que se había solicitado - ¡tenía razón! - y luego supe que mi colega y amiga Mariza Peirano, estudiante del doctorado en Antropología iba, justamente, a enfrentarse a nuestro toro (Florestan). Su dedicación a Florestan dio lugar a un capítulo muy bello en su tesis de doctorado y yo me rendí "apenas" al proyecto freyriano... (Debo agregar, si respondiera a las cuestiones del Simposio, que los textos de Mariza Peirano están entre los más destacados producidos en el campo del Pensamiento Social).

En relación al impacto de la producción de Gilberto Freyre en el exterior, los capítulos - particularmente el primero y el segundo de este libro, pero especialmente el primero - se volvieron para mí un desafío, ya que me parecía necesario publicar algo en inglés justamente cuando Gilberto llamaba menos la atención en el mundo anglosajón y europeo, de los años '70 en adelante.

Presenté el texto sobre Gilberto (capítulo 1 del libro) a un journal dirigido por Thomas Skidmore, creo que con el respaldo de Brown University. Esto fue cerca de 1979. Personalmente creía que el texto era bueno, los miembros de mi comité lo habían elogiado... confiaba en que iba a ser publicado. Sin embargo, una carta de Skidmore me informó de que un evaluador había rechazado el texto; en el sobre estaba la evaluación, la cual me pareció despreciable. Respondí a la evaluación, punto por punto, dactilografié (en aquellos tiempos...) varias páginas en defensa de mi texto. Skidmore mantuvo el rechazo. Me dio la impresión, en la época, y hoy tengo aún más seguridad, de que la evaluación se hizo para "quemar" el texto de un alumno brasileño, en parte por la decisión u orientación tendenciosa del propio Editor. Fui a Estados Unidos sin documentos, mi orientador no era un brasilianista, yo no había, digamos, cumplido con esa especie de ceremonia o ritual casi que propiciatorio, para publicar en una revista "de peso" en Estados Unidos. Me aseguré de la mala intención cuando traduje el texto y lo presenté al Anuario Antropológico, dirigido por Roberto Cardoso de Oliveira. Aceptaron el texto rápidamente - y tuve el honor, en el volumen de 1983, de publicar en compañía de artículos de David Maybury-Lewis, Julio Cesar Melatti y Delma Pessanha Neves, entre otros excelentes textos. Fue para mí una revancha. 
Al volver a Brasil y leer y releer la producción de una vida entera de Gilberto Freyre, tuve una sensación muy fuerte - que explica, quizá, la mayor cantidad de capítulos que dedico al Maestro de Apipucos en este libro. Fue la percepción de una caída de calidad que se acentúa en sus obras, a partir de sus 50 o 60 años. Como Gilberto nació en el cambio de siglo, es en los años 50 cuando se percibe una fragilidad en sus escritos, hasta entonces inexplicable para mí. Buscando una explicación desarrollé lo que ahora se presenta como capítulo tres del libro, que recibió de Antonio Candido una consideración generosa sobre mi contribución a una "sociología de la vanidad", por abordar los factores o condiciones que habrían influenciado al hombre y autor Gilberto, en su trayectoria descendente, anclada en Recife. Hubo lecturas que me resultaron muy injustas en ese capítulo sobre "el espíritu de la aldea" en la producción de Gilberto. Como el escenario del texto se coloca en torno a sus amigos y camaradas en Recife, hubo quien me llamó “imperialista del sur" (?) o notó un "determinismo mesológico" en mi análisis. Una lectura más atenta se habría percatado de que el texto es una reflexión sobre el escenario de interacción social y afectiva que fue desfavorable a la producción del autor - que nada tiene que ver, de ninguna manera, con "Recife". Dígase aún, tal burrada sería impensable, en la tierra de João Cabral de Mello Neto, Evaldo Cabral de Mello y Ulisses Pernambucano de Mello (todos nombres notables y sus parientes). Lo que de hecho está en juego, en ese capítulo, es el tipo de interacción social en relación a nuestro autor. ¿Cuáles son los nuevos "significant others" frente a los cuales se configura su identidad, ya cincuentón? Este es el argumento del texto: a partir de determinado momento de su vida, el autor Gilberto se vuelve un actor - un mal actor - buscando reconocimiento y aprobación. Y esto tiene un efecto desfavorable en su obra.

RZ: Volvamos a los autores analizados en su obra. Usted argumenta que el autor de Casa-grande \& Senzala tuvo más éxito al hablar de las clases dominantes que al hacerlo de las clases populares. ¿Cree usted que este hecho puede impedir, actualmente, un reconocimiento más profundo de la obra de Freyre?

Luiz Antonio de Castro Santos: Estoy seguro que sí, por desgracia. Y esto supone un trastorno para el debate sobre el pensamiento social y político en Brasil. En los días de hoy, el "rechazo" a las obras de Freyre (a los libros del "primer" Freyre - autor de Casa-grande \& Senzala, de otra obra maestra que es Nordeste, además de Sobrados e mocambos) es al mismo tiempo rechazo a la necesidad de que entendamos cómo, a partir del pasado señorial y hasta los días de hoy, particularmente en el terreno pantanoso de la política, las clases dominantes manipularon y manipulan de forma espantosa a las clases populares. Todo está ahí, en tono mayor y de tragedia griega, en fragmentos de la primera obra de Gilberto Freyre. Es leer, para creer.

\section{Del otro lado del Charles River: la travesía}

Mariana Leoni: En su formación académica, iniciada en la Pontificia Universidad Católica de Río de Janeiro y que completa en la Universidad de Harvard, usted participó en el máster de la Escuela de Salud Pública, también en Harvard. ¿Qué significó esta experiencia para su carrera? Uno de los capítulos de su libro, por cierto, aborda el tema del pensamiento sanitarista y otro discute temas de educación y salud a inicios del siglo XX.

Luiz Antonio de Castro Santos: Aún como estudiante de sociología, en Río de Janeiro, algunos profesores dejaron una huella duradera en mi formación, cautivaron mi atención. Los estudios demográficos durante el curso, tanto las cuestiones sobre mortalidad, como las de fecundidad, se convirtieron en un puente para ir centrando la atención en temas de salud. Mi propio background familiar reforzaba, tempranamente, mi camino hacia el estudio de temas de salud. Algo en la línea de los "significant others", destacados por los interaccionistas. Mi padre, formado en medicina en 1938, 
mi abuelo, diplomado en 1908 - con él viví en Río de Janeiro, mientras cursaba la facultad -, además de otros antepasados, también médicos, cuyos estudios de medicina se remontaban al siglo XIX en las facultades de Bahía y Río de Janeiro. Estas facultades se destacaban, en aquellos tiempos, por la inspiración francesa y producían médicos con mejor formación que la de los colegas de "América". Fueron, por cierto, las enormes deficiencias en la enseñanza médica de aquella época lo que motivó el conocido Relatório Flexner, en 1910, que denunció y arrasó con la precariedad de las escuelas de medicina en aquel país. Cuando me presenté a la prueba de ingreso para ciencias sociales, en la Universidad Católica de Río de Janeiro, recuerdo haber encontrado una figura amiga de mi familia, el padre jesuita Fernando Bastos de Ávila, excelente sociólogo doctorado en Louvain, que me preguntó por los motivos para no seguir la carrera médica... "Hay demasiados médicos", creo que le respondí.

De este modo, si un joven estudiante se encontrara frente a decisiones difíciles, no vacilaría en sugerirle que opte por caminos cruzados, por trayectorias abiertas a la diversidad del saber. Creo que fue esto lo que hice. El interés por la historia se sumó a los intereses por la demografía - "Demografía Histórica”. Y la sociología cerró, jo abrió aún más!, el círculo. Recién formado en sociología, me vino como anillo al dedo la indicación para una beca del Population Council, en 1973, para cursar el máster en Estudios Poblacionales en la School of Public Health, en Harvard. El curso se localizaba en una región bastante céntrica de Boston, donde estaba la Escuela de Medicina, además de la Escuela de Salud Pública. Lo que me sedujo, al aceptar esta indicación para la beca, por haberme destacado en la disciplina de Demografía que cursé en la graduación, fue la posibilidad de extender e integrar mis estudios a las ciencias sociales; al campo de salud poblacional (hoy en día se usa mucho el término "salud reproductiva"); a la historia demográfica (me fascinaba The world we have lost, libro creado por el Cambridge Group for the History of Population and Social Structure, fundado por Peter Laslett). Quizá hoy en día lo diría de forma más simple: la posibilidad de profundizar en el estudio de las "ciencias humanas y sociales en la salud".

De esta forma inicié mi máster, en septiembre de 1973. Para mi sorpresa, la orientación del curso era, desde las primeras semanas, algo autoritaria. En primer lugar, se me impuso un tema para la disertación (que yo no acepté, no porque fuera un tema ilegítimo, sino porque me era impuesto); en segundo lugar, percibí que se trataba de un camino académico inspirado en los programas de control poblacional, que en ese momento estaban muy de moda en las Américas y en Asia, particularmente en la India, como "campo experimental". Me acuerdo de algunos profesores, más ideólogos del "population control" que, de hecho, investigadores estudiosos. Uno de ellos, el Profesor John B. Wyon, dirigió un programa de planificación familiar en aldeas de Punjab y recibió, de un crítico indio, una refutación acerca de los resultados del programa "family planning" financiado por los norteamericanos. Sin vacilar, me rebelé igualmente ante ese camino, participando activamente en seminarios y clases. La oposición de la Iglesia Católica brasileña, desde sus sectores de izquierda liderados por Don Helder Câmara, daban respaldo a mi resistencia. A decir verdad, yo también tomaba de las ciencias sociales de carácter libertario -sobre todo del marxismo de Karel Kosik, filósofo checo, teórico admirablelas ideas para resistir a una orientación de los alumnos casi colonizadora, "otra" Harvard hasta hoy irreconocible para mí. También, posteriormente noté que la mayoría de los alumnos venía de países subdesarrollados, más que nada de Asia y África. Era una especie de "Harvard para el Tercer Mundo", al igual que la conocida "Ed School", la Facultad de Educación, que también podría caracterizarse de este modo. Sin embargo, la diferencia entre los dos campus, el de Boston (Salud Pública) y el de Cambridge (Educación), estaba en la tendencia de izquierda que se encontraba en este último. Estábamos en la década de 1970 y en los cursos de la "Ed School" ya se leía a Paulo Freire con buenas traducciones.

Para mi formación en salud pública fue importante el aporte de las ciencias sociales y del pensamiento histórico, absorbido por los escritos éticos-políticos de Benedetto Croce y R. G. Collingwood. Aun así, creo que esas lecturas eran más una influencia de mi graduación en Brasil -reconozcamos, una excelente 
marca de calidad que nos preparaba para enfrentar cualquier curso en el exterior sea tanto en EE. UU. como en Europa - ya que el ambiente de reflexión sobre las ciencias sociales era bastante raro en la Escuela de Salud Pública, en Boston. Por caminos sinuosos, fue justamente años más tarde, ya siendo alumno del doctorado en sociología, en el campus de Cambridge, en los alrededores de Harvard Yard, que aquella amalgama de conocimientos dio sus frutos.

No quiero dejar la impresión de que el máster en Populational Studies, en la School of Public Health, fuera un desastre. Desde la perspectiva de la crítica ideológica y política, la influencia sobre los estudiantes era inadecuada, si no errada. Pero es necesario decir que, en la Escuela de Salud Pública, la formación técnica, en métodos epidemiológicos y en "métodos y materiales" sobre demografía era bastante buena y daba a los alumnos una base sólida con la cual volver a sus países de origen. Y hago referencia desde ya a uno de los profesores más "seniors" de la School of Public Health, Nathan Keyfitz, especialista en demografía matemática, sociólogo capaz, fundamentalmente en el terreno de estudios urbanos. Aún más, como también participaba en el curso docente del Departamento en Sociología, en el campus de Cambridge (Arts and Sciences) tenía interés en que algunos de nosotros, del área de estudios poblacionales, volviéramos a las ciencias sociales.

El hecho de que yo cursara, ya en 1970, un programa de Especialización en Demografía, montado en la PUC de Río de Janeiro por profesores del CELADE, el respetadísimo Centro Latinoamericano de Demografía, con sede en Santiago de Chile, me aproximó a Keyfitz que - como ya mencioné, - además de ser un mathematical demographer, era un sociólogo atento a las dimensiones de la de Demografía Social y a los estudios urbanos. Me acerqué a él en cuanto percibí su apertura intelectual, y fue escuchando sus consejos que se me presentó la "aventura" del doctorado en sociología en Harvard. Para poder seguir con mi proyecto, su estímulo y asesoramiento fueron esenciales.

ML: Cursar doctorados en el exterior era algo frecuente en su generación, que se graduó en los años 1960/70 y buscaba hacer la posgraduación fuera de Brasil, inclusive para escapar de los años de plomo de la dictadura. No se hablaba de "posdoctorados", periodos marcados, hoy en día, por temporadas más cortas que el tiempo demandado para un doctorado. ¿De qué modo esta estancia prolongada fuera del país influenciaba las carreras académicas de los jóvenes "PhDs", fundamentalmente cuando volvían a sus países de origen?

Luiz Antonio de Castro Santos: Creo que, cuando hablé de las condiciones favorables al enriquecimiento de la historiografía con las ciencias sociales (y del foco de atención sobre la salud, en particular), los rumbos más estimulantes para mi formación como investigador se revelan, de hecho, en el Departamento de Sociología. En el otoño de 1974 comencé mis estudios de doctorado "del otro lado de Charles River". Curiosamente, esta travesía tenía un significado simbólico muy fuerte: al despedirme de algunos colegas del "medical area" de Boston, escuché algunos comentarios, entre elogiosos e irónicos: "Now Luiz is going to be a real PhD".

Mi relato es personal y, por así serlo, puede ser dispensable. Sin embargo, hoy en día los posdoctorados son muy frecuentes y la figura del tutor, muy importante. En aquella época, los doctorandos de las carreras de Arts and Sciences en Harvard, podíamos disfrutar del acompañamiento informal de un docente, mientras no estuviese definida la elección de un tutor, del "thesis advisor". El Profesor Keyfitz fue justamente todo aquello que hoy en día se espera de un tutor atento de posdoctorado, genuinamente interesado por el proyecto de investigación. Mi relato es, por lo tanto, de interés para los jóvenes doctores actuales, decididos a iniciar un posdoctorado.

Keyfitz disfrutaba practicando su elegante español y me hablaba en ese idioma cuando nos encontrábamos en su oficina en el William James Hall. Una vez le lleve un ejemplar de El Pensamiento Crítico en Demografía, del filósofo brasileño Álvaro Vieira Pinto, que había sido, antes del Golpe de 
Pinochet, investigador "senior" del CELADE. Este encuentro fue cerca de 1976. El libro era una publicación reciente. Keyfitz me lo devolvió algunas horas después en su oficina, decepcionado. Vieira Pinto ofrecía una visión panorámica, una síntesis para un tema amplio. No era esa la preocupación de un demógrafo fascinado por los modelos matemáticos. Pero cuando se acercaba la hora de elegir cursos, o incluso de invitar a un tutor, los consejos de un scholar de su categoría eran fundamentales. Digamos que nadie nos imponía elecciones, estas eran facilitadas por un "cuaderno" detallado, que especificaba los intereses de investigación de profesores y colegas, hasta de los más antiguos. Algunos (como yo más tarde) se tomaban licencias durante largo tiempo, los plazos eran flexibles. Había colegas que llevaban matriculados en el doctorado desde hacía cinco, seis o siete años.

En 1974, los alumnos matriculados en el programa de Sociología eran cerca de cincuenta, entre los cuales media docena eran extranjeros, incluyéndome (el único latinoamericano), colegas asiáticos y dos europeos, siendo uno de ellos Víctor Pérez-Díaz, tal vez uno de los pocos estudiantes con libros ya publicados. La presencia femenina era considerable (incluso en el cuerpo docente) y teníamos colegas y profesores afrodescendientes. Entre ellos, un joven profesor jamaicano, Orlando Patterson, especialista en sociología histórica de la esclavitud. En la "Faculty" estaban los pesos pesados, como por ejemplo los respetados profesores Daniel Bell (el desvalorizado autor de The end of ideology, título desastroso, que oculta los méritos de la obra); el gran Gino Germani, "visiting professor", que llegó directamente de Buenos Aires, invitado, si mal no recuerdo, por Talcott Parsons, que se jubiló en 1973; David Riesman, autor de la celebradísima obra The lonely crowd: a study of changing American character, que durante la graduación, en Brasil, leíamos en español: La muchedumbre solitaria; George Homans, un autor un tanto behaviorista para nuestro gusto, pero un scholar notable, que recibió a los nuevos estudiantes en la ceremonia de bienvenida, citando en latín.

El departamento era sólido y envidiable, por la variedad de trayectorias de los investigadores ilustres, e incluso de los "associates" y "assistants". Había visitantes ilustres, entre los cuales se destacaba, por la competencia, energía personal y disposición constante, Magali Sarfatti Larson -al igual que Germani, también con raíces en Italia y Argentina, mucho más joven que Gino- que acababa de escribir The Rise of Professionalism, obra que luego se asentó de forma vigorosa en la literatura sobre profesiones y sus nichos de poder. Entre los asistentes y asociados, en el departamento, había buena confraternización con los estudiantes, lo que facilitaba las aproximaciones, el intercambio de información y consejos (y advertencias...) sobre disciplinas y tesis futuras o ya en proceso. Esta proximidad diaria con los más jóvenes de la Faculty tuvo, de hecho, un gran impacto sobre nuestros proyectos académicos. En mi caso en particular, establecí un excelente vínculo con Paul Starr y Gösta Esping-Andersen. El primero fue mi tutor de tesis: muy interesado en temas relativos a la historia de la salud y la medicina, lector atento de los trabajos de sus alumnos, autor de un brillante libro sobre The social transformation of American medicine, una excepcional narrativa histórico-sociológica. (En la edición del FCE, México, La transformación social de la medicina en los Estados Unidos de América, 1991 -un título infeliz en español, ya que le falta el subtítulo que destaca los méritos de la obra, sobre el surgimiento del complejo médico-industrial y la hegemonía de la profesión médica en aquel país). Un libro imperdible. Fue Starr quien me sugirió el título de mi tesis: Power, Ideology and Public health in Brazil: 1889-1930. Nunca llegué a publicarla, pero de ella extraje la base, o fundamento, para publicar varios papers de carácter histórico-sociológico sobre el tema. El simpático Gösta Esping-Andersen, nacido en Dinamarca, vino a Harvard después de formarse como doctor en Wisconsin. En la fase final de producción de mi tesis, Gösta conformó un dúo fantástico con Starr, ya que se interesó por mi trabajo al punto de contribuir con sugerencias y ajustes muy valiosos. Andaba siempre por Cambridge, incluso por los corredores del William James Hall, con un lindo Golden Retriever, cuyo nombre lamentablemente no recuerdo. (Pero si guardé en mi memoria su carácter amigable y ágil, siempre listo para recibir afecto). Años más tarde, como profesor en Italia, Gösta publicó Politics against Markets (1985) y, en seguida, su extraordinario libro The Three Worlds of Welfare Capitalism, editado en seis países. Starr es actualmente profesor en Princeton y Esping-Andersen, en la Universitat Pompeu Fabra, en Barcelona. 


\section{La agenda internacional}

RZ: En la introducción, usted expresa preocupación por la adhesión de los estudiantes a lo pautado en la agenda de metrópolis internacionales en perjuicio de la búsqueda de una reflexión que no se aleje por completo de nuestra realidad. ¿Cree usted que la universidad puede, aún, cambiar esta tendencia?

Luiz Antonio de Castro Santos: Sospecho que tenemos que superar, para cambiar tal tendencia, algunas dimensiones de lo que llamo "subalternidad" en relación al centro o a las metrópolis internacionales. Está en todos nosotros, no apenas entre los estudiantes. A decir verdad, la crítica a un discurso hegemónico imaginado de nuestros clásicos - hegemonía de autores antiguos sobre las generaciones actuales - es errónea. La hegemonía es externa. Los excesos de vocaciones centradas en el plano "micro", casi "tribales", por ejemplo, son un producto norteamericano. Conozco colegas, en Estados Unidos, que no dominan la literatura sociológica con la que se formaron sus maestros y que formó a mi generación, pero que se han vuelto "especialistas" en género, en "racial studies", etc. Hay un enquistamiento espantoso, que traiciona nuestras mejores tradiciones en las ciencias humanas. Es una pena que, justamente, no seamos hegemónicos, si se me permite la ironía. Siempre rendimos tributo a las voces de fuera.

Un ejemplo sorprendente se encuentra en los trabajos de Boaventura de Souza Santos, cuya crítica al descuido del centro en relación a nuestras periferias, no tiene en cuenta que incluso nuestros y nuestras colegas de Lisboa, Coimbra o Braga tienen la mirada puesta en Francia, Inglaterra o Estados Unidos -y no en nosotros. No hay diálogo con nosotros, más allá de alguna pequeña referencia de rutina. Esto vale para Boaventura, cuyo círculo e impacto internacional desconocen la producción brasileña. Estoy convencido, hoy, de que deberíamos abrir nuestras puertas a alumnos portugueses para que hagan posdoctorados serios con nosotros, no privilegiar la dirección inversa: alumnos nuestros haciendo doctorados y doctores recientes haciendo "posdoctorados" en Portugal. Para ser justos, si quisiéramos medir "impactos", la consolidación de las ciencias humanas en Brasil data de los años 30, mientras Salazar momificó la vida académica portuguesa durante 40 años.

La situación no se resume a las relaciones desiguales de poder simbólico, como revelan los Congresos "Luso-Afro-Brasileños" o a la distribución de poder en el interior de la International Sociological Association, que de hecho es una asociación "europea" de sociología. La subalternidad (no hablo aquí de influencias, que es otra cosa, como diría Antero de Quental) está presente también en las relaciones con la comunidad anglosajona. Véase lo que ocurrió con una moda reciente, aquí e incluso en Portugal: numerosas citas de un texto de Michael Burawoy en defensa del intelectual público, o de una "sociología pública". Ahora bien, la defensa de la participación de los científicos sociales en la arena pública, en el caso de Burawoy, remite a un debate interno, sobre todo a la crítica que él hace a sus colegas de sociología en los Estados Unidos. Si tomamos el concepto seriamente, como una defensa para "traer de vuelta al Estado" (Scokpol), ¡tendremos que situarlos nuevamente en su gestación en América Latina!!! Basta pensar en Florestan Fernandes, que fue un Intelectual Público toda su vida, incluso antes de que Burawoy terminara el College... Y en lo que respecta a la discusión del Estado, no necesitamos, a diferencia de los linajes académicos de Harvard y otros lugares, "traerlo" de vuelta. La atención sobre las cuestiones del Estado y la Sociedad forma parte de nuestro ADN latinoamericano. Basta recordar los textos de Faoro y, en mi generación, de Guillermo O’Donnell. El tema ya nos atraía, mucho antes de que Theda Scokpol terminara su doctorado de sociología en Harvard. Sobre el tema correlativo del Institucionalismo o Neoinstitucinalismo - también moneda corriente en el debate internacional, inclusive entre latinoamericanos - surge el mismo problema de "ideas fuera de lugar". Las vertientes más profundas de lo que hoy se denominan (neo) institucionalismos no están ahí afuera, en el grupo formado por Scokpol y por colegas de Harvard de su época, como Rosemary C. R. Taylor. Fueron una contribución rigurosamente latinoamericana. 
Si recurrimos al pensamiento sociológico que es fuertísimo en México, encontraremos las Siete Tesis Equivocadas sobre América Latina, un texto de Rodolfo Stavenhagen, de 1965, leído y discutido por mi generación; rigurosamente "institucionalista" es la contribución de Pablo González Casanova, cuya obra Sociología de la Explotación data de 1969. En Brasil, Wanderley Guilherme dos Santos escribió Cidadania e justiça: a política social na ordem brasileira, obra publicada en 1979, que me estimuló a destacar su carácter pionero, en un texto en el que me centré en la Era Vargas. El subtítulo revela mi postura: "Aún el testamento de Vargas: Institucionalismos a parte".

No cabe sugerir que el debate latinoamericano debería descartar las contribuciones del grupo "neoinstitucionalista" norteamericano. Lo que defiendo es que nuestra propia producción se remita siempre a las tradiciones más profundas, en América Latina, antes de pagar, de forma apresurada, tributos a quienes nos ven desde fuera, sobre todo en inglés, en circuitos internacionales muy bien orquestados. Las raíces del pensamiento social considerado institucionalista brotaron primero en contribuciones en portugués o español.

Veamos, en Brasil, lo que sucede con los llamados "invitados internacionales", que son recibidos de forma fraterna y festiva como oradores en nuestros Congresos. Si acompañamos su retorno a sus centros de origen, impresiona ver como no dejamos ninguna huella en sus obras - incluso cuando publicamos en inglés, en revistas creadas para nuestros colegas que no dominan el portugués... Nuestros Clásicos tienen una importancia excepcional, y no me parece que la estatura internacional de Sérgio Buarque de Holanda - hablo aquí de raíces, de erudición y competencia ejemplares, no del "impacto allá afuera"- tenga que ver con viajes a congresos en el exterior, a los cuales vamos a oír, no a ser oídos. La trayectoria de Gilberto Freyre es peculiar, como sugiero en mis capítulos sobre su obra; pero diría que sus peripecias internacionales fueron importantes en su carrera, ya que él viajaba a Europa para dar conferencias, no como mero asistente.

\section{Lecciones de (y para) un aprendiz}

ML: En lo que respecta al perfil intelectual, ¿tiene un $P h D$ en ciencias humanas y sociales, de las décadas de 1970 y 1980, características similares a lo que se encuentra actualmente? ¿O hay elementos de la formación, en el pasado, que no se manifiestan ya en las carreras de los más jóvenes?

Luiz Antonio de Castro Santos: Al ser posible escapar de las carreras contra el tiempo para terminar nuestras tesis de doctorado, al poder extender nuestra estancia en la universidad durante varios años, esto nos permitía desarrollar una base intelectual sólida.

Digo esto sin vacilar. El hecho de que la duración de un doctorado fuera más flexible, a veces prolongándose durante años sin interrupción, tenía un efecto excelente sobre la diversidad de intereses. En seminarios de carácter interdisciplinar - algo que está de moda hoy en día, aunque rara vez se revelen, de hecho, "interfaces" o "interdisciplinaridades" -, cada uno de nosotros, estudiantes de ciencias humanas de aquellos tiempos (como ejemplo de las buenas universidades norteamericanas), mostrábamos un potencial de "verse en el otro", de cultivar una mirada abierta a diferentes metodologías, perspectivas y objetos. Esto, desde mi punto de vista, se perdió. Y dicho potencial debe recuperarse hoy.

Insisto en este punto. En las décadas de los '70 y ' 80 , si se nos provocaba para debatir, podíamos tratar o abordar temas más allá de nuestro "tema de tesis". Ya nos centráramos en estudios sobre raza, sexualidad o género, capitalismo, centro y periferia, mundo rural, estudios urbanos y violencia, ciencia y tecnología, entre tantos cortes del mundo social, teníamos algo sustancial que decir. Y desde el punto de vista teórico-metodológico, teníamos tiempo para profundizar en métodos "cualitativos" 
y "cuantitativos", profundización que es imperativa y que cuando está ausente, produce adhesiones de último momento. Temo que tal restricción del saber y la pérdida de esas bases sean el resultado de los doctorados cortos, casi prêt-à-porter, que muchos programas de "pos" imponen a las nuevas generaciones.

Los primeros programas de "posdoctorado", en Harvard, tenían un sentido concreto: profesionalizar. Era una cuestión de mercado, de ubicación profesional, en un país que ya mostraba una multitud de PhDs. Por ejemplo, un PhD en cierta área de Humanas hacia un "pos-doc", una pasantía corta, con objetivos prácticos y metas precisas, en Harvard Business School; de este modo, el joven doctor creaba de cierta forma alternativas para su inserción en el mercado de trabajo (extremamente competitivo). Por otro lado, si después de haberse formado como doctor alguien se asociaba durante determinado tiempo a un centro de investigación en Europa, esto era una "pasantía", en general una "fellowship", punto final. No había un nombre para eso, como si fuese algo "esperado" en la formación. El propio término usado por muchos colegas jóvenes: "soy posdoctor en..." no tiene ningún sentido. No hay, de hecho, un título de "posdoctor".

Creo que si quisiéramos producir pasantías de pos-doc de alta calidad, algo un tanto diferente de lo que se ve actualmente tendría que ser considerado, no la continuidad de la atención sobre el tema de doctorado, sino la búsqueda de un escenario mayor, la construcción de un perfil más diverso, que implique la interacción con orientadores que no sean especialistas en el área de la tesis ya defendida. El pos-doc, de este modo, será un paso rumbo a una postura rigurosamente interdisciplinar. Este es el mayor objetivo de la publicación de O pensamento social no Brasil: proponer temas, "estilos e idioma" para el país, que se coloquen más allá de cortes y visiones segmentadas, aunque sin ignorar su existencia o descuidar su importancia.

Esto significa tomar seriamente la distinción conceptual y empírica, elaborada hace más de cien años por Ferdinand Tönnies, entre "comunidad y sociedad". Si hablamos de estudios de género, estamos frente a gemeinschaft, "life-forces" (como traducía Louis Wirth) asociadas a emociones, a hábitos, a conductas de un colectivo fundamental. Una tesis de doctorado sobre género -identidades, subjetividades, papeles, estigmas, subordinación, luchas- se abriría necesariamente, en un pos-doc, a una reflexión en la cual las dimensiones de género se sitúan frente a los mecanismos estructurales (políticos, económicos) y a las fuerzas societarias. O sea, la búsqueda de un fundamento teóricoanalítico de carácter gesellschaft. Tal alteración es un movimiento de traducción, o una dialéctica de la transferencia, entre una visión societaria y el terreno de las cuestiones de género. Estoy convencido de que mi generación estaba preparada para establecer los nexos entre los "mundos sociales" divisados por Tönnies, sin descuidar aquel objeto específico, privilegiado en nuestras tesis. La misma marcha acelerada que caracteriza la producción de textos en la pos, la aceptación de tiempos y movimientos impuestos por normas y dispositivos curriculares es un estímulo a la construcción de perfiles académicos fragilizados y segmentados.

\section{Agradecimientos}

RZ: Finalmente, O pensamento social no Brasil abarca temas diversos, sin distanciarse de la cuestión del pensamiento social. ¿Qué lector espera usted alcanzar con esta nueva edición?

Luiz Antonio de Castro Santos: En primer lugar, quiero agradecer al equipo de la nueva EdUERJ la edición primorosa de mi libro, en convenio con la editorial Gramma. El cuidado editorial es un regalo a los lectores. En segundo lugar, agradecer también la autorización de los editores para publicar esta entrevista en la Revista de Estudios Brasileños, ahora en una versión extendida. 
- EL PENSAMIENTO SOCIAL EN BRASIL. ESTILOS, IDIOMAS:

ENTREVISTA CON LUIZ ANTONIO DE CASTRO SANTOS

RICARDO ZENTGRAF - MARIANA LEONI BIRRIEL

En lo que respecta a su pregunta, deseo alcanzar al lector o lectora que se interese por los temas del Pensamiento Social, por la tradición rica de los "estilos de pensamiento" de Karl Mannheim. Creo que será una lectura placentera. El libro, en la presente reedición, es precioso, no uso jerga, creo que los temas que trato son absolutamente actuales. E incluso un texto que, digamos, parecería que "escapa" a las preocupaciones centrales de la obra, que es el capítulo sobre la agricultura del café en África en los años '50, nos remite al panorama actual, nuestro, de producción en monocultivo para la exportación y de negligencia de la agricultura alimentar. Justamente lo que aborda nuestro Gilberto en su magistral Nordeste: aspectos de la influencia de la caña sobre la vida y el paisaje del Nordeste de Brasil. Un libro premonitorio, de 1939. 


\section{NOTAS}

${ }^{1}$ Traducción de Mariana Leoni Birriel. Revisión de Esther Gambi.

\section{REFERENCIAS BIBLIOGRÁFICAS}

Almeida Filho, N. (2014). Nunca fomos flexnerianos: Anísio Teixeira e a educação superior em saúde no Brasil. Cad. Saúde Pública. Rio de Janeiro, 30, 12, 2531-2553.

Botelho, A. (2005). O Brasil e os dias: Estado-Nação, modernismo e rotina intelectual. Bauru: Edusc.

Buarque de Holanda, S. (1955). Raíces del Brasil. Ciudad de México: Fondo de Cultura Económica.

Buarque de Holanda, S. (1987). Visión del paraíso: motivos edénicos en el descubrimiento y colonización del Brasil. Caracas: Biblioteca Ayacucho.

Buarque de Holanda, S. (1992). $3^{\circ}$ Colóquio UERJ. Rio de Janeiro: Imago.

Casanova, P. G. (1969). Sociología de la explotación. México: Siglo XXI Editores. Disponible en [http:// bibliotecavirtual.clacso.org.ar/ar/libros/secret/gonzalez/ parte1.p].

Castro Santos, L. A. (2018). Reabrindo o debate sobre Jorge Nagle, a educação e a saúde na historiografía brasileira. En L. A. Castro Santos \& L. Faria. Saúde, sociedade, protagonismos. São Paulo: Hucitec.

Castro Santos, L. A. (1985). A casa-grande e o sobrado na obra de Gilberto Freyre. Anuário Antropológico, 83, 73-102.

Castros Santos, L. A. (2017). Duas visões do paraíso: convite a Todorov para ler Sérgio Buarque de Holanda. En L. A. Castro Santos. O pensamento social no Brasil: estilos, idiomas. Rio de Janeiro: EdUERJ \& Gramma Editores.

Esping-Andersen, G. (1993). Los tres mundos del estado del bienestar. Valencia: Edicions Alfons el Magnanim.

Freyre, G. (1936). Sobrados e mucambos. Rio de Janeiro: Ed. Nacional.

Freyre, G. (1973). Nordeste. Madrid: Espasa.

Freyre, G. (1977). Antología. Madrid: Cultura Hispánica.

Freyre, G. (2010). Casa-grande y senzala. Madrid: Marcial Pons.

Larson, M. S. (1977). The rise of professionalism: Monopolies of competence and sheltered markets. Berkeley: University of California Press.

Laslett, P. (1971). The world we have lost. London: Methuen.

Nogueira, O. (1998). Preconceito de marca. As relações raciais em Itapetininga (apresentação e edição de Maria Laura Viveiros de Castro Cavalcanti). São Paulo: Edusp. 
- EL PENSAMIENTO SOCIAL EN BRASIL. ESTILOS, IDIOMAS

ENTREVISTA CON LUIZ ANTONIO DE CASTRO SANTOS

RICARDO ZENTGRAF - MARIANA LEONI BIRRIEL

O'Donnel, G. (1975). Reflexiones sobre las tendencias generales de cambio del Estado burocrático-autoritario. CEDES/ G.E. CLACSO, 1.

Paz, O. (1959). El laberinto de la soledad. Ciudad de México: Fondo de Cultura Económica.

Pinto, A. V. (1973). El pensamiento crítico en demografía. Santiago de Chile: Centro Latinoamericano de Demografia - CELADE.

Riesman, D. (1964). La muchedumbre solitaria: un estudio sobre la transformación del carácter norteamericano. Versión castellana de Noemí Rosenblat. Buenos Aires: Paidós.

Santos, W. G. (1979). Cidadania e justiça: a política social na orden brasileira. Rio de Janeiro: Editora Campus.

Starr, P. (1991) La transformación social de la medicina en los Estados Unidos de América. México: Fondo de Cultura Económica.

Stavenhagen, R. (1981). Siete tesis equivocadas sobre la América Latina. El Día. 25 junio, 1965. México: Nuestro Tiempo.

Tavolaro, S. (2011). Cidadania e modernidade no Brasil: crítica a um discurso hegemônico. Rio de Janeiro: Annablume.

Todorov, T. (1987). La conquista de América: la cuestión del otro. México: Siglo XXI. 